\title{
Causality and the Reduction to Art of Simon Stevin's Mechanics
}

\author{
Maarten Van Dyck
}

\section{Bringing mechanics to the form of Art}

Simon Stevin is a seminal author in the so-called 'renaissance of mathematics'. ${ }^{1}$ His vernacular books on statics and hydrostatics (published together in 1586) not only helped readers to become familiar with Archimedean mechanics, but they also contained strikingly innovative additions, such as his proof of the law of the inclined plane and the hydrostatic paradox. They also stand out for their self-confident character: Stevin was well aware of the novelty of his approach, and he claimed in the introduction to his text that he was the first author to allow statics, which he called the 'art of weighing' (weeghconst), to 'come to the form of Art'.

The idea that a field of practical operations could be subject to what was usually called 'reduction to art' was very common in the period. ${ }^{3}$ It was an idea with ancient Ciceronian precedents that had become imbued with the Renaissance notion of method. The ideal was to provide a systematic, textual presentation that would bring as many actions as possible under the purview of a small number of principles that allowed one quickly and efficiently to decide on how to proceed to attain one's goals. Stevin's books from 1586 did not provide many explicit statements on how he understood this ideal, but we can read his discussion on the 'restoration of the Age of the Sages', included in his Wisconstighe Ghedachtenissen (published in 1605-1608), as an articulation of the method behind his attempted 'reduction to the form of art'.

Stevin introduced five components that characterize the order to be followed in the written presentation of any art. ${ }^{4}$ One should start the presentation by laying out the definitions of all the constwoorden (terms of art). One should then strive always to express similar things with similar words throughout the text (using what is known in rhetoric as anaphora), so that their relation is immediately clear. Each proposition in the treatise should be presented according to the model provided by Euclid's Elements, clearly separating the different parts, such as the givens, proof and conclusion. This not only transparently exhibits the deductive structure responsible for the proposition's truth, but it should also allow each reader immediately to identify the part he is interested in on different occasions. Using properly constructed dichotomous divisions (visually presented at the opening of a text in the typical tables using curly brackets) allows one immediately to see that the text as a whole offers a complete treatment of its subject, without leaving out any parts, and that its parts will be presented in the right order, where later parts presuppose earlier parts but not the other way around. Interestingly, these tables will also help rationalize the inverse translation back into practice, by functioning as a kind of decision tree that allows all the relevant options to be seen at a glance. ${ }^{5}$ And lastly, one should present the theoretical treatment separately from the practical applications that form its ultimate goal, so that the specifically systematic character of the former can be grasped by the reader. As stressed by Stevin, this will again aid the decision process by allowing one easily to locate the theoretical proposition relevant for the 
particular purpose at hand, without having first to separate it from any other, extraneous practical operations that have been included unnecessarily in the presentation.

In what follows, I will offer an analysis of how Stevin's books on The Principles of the Art of Weighing (Weeghconst) and The Practice of Weighing (Weeghdaet) can be seen as exemplifying this typical Renaissance ideal of reduction to art. ${ }^{6}$ There was yet another prominent discourse concerning the arts, though, and I will also try to see how this relates to Stevin's endeavor. According to the Aristotelian conception, the arts are characterized by two features: that they aim at useful ends, and that they do so by investigating the causes of things (see, e. g., the first chapter of the first book of the Metaphysics). Any reflection on the notion of causality is conspicuously missing from Stevin's characterization of the proper order to be used in the arts, but this did not stop him from using causal terminology throughout his texts. Thus, how is his use of causal language related to the ideal of a reduction to art? As we will see, Stevin's text on dialectics, or what he calls Bewysconst ('the art of demonstrating'), which he published a year before his books on statics, offers a number of important clues. This text also bears many hallmarks of the ideal of reduction to art, but it has the added interest that because of the traditional nature of its subject matter, it also engages explicitly with the Aristotelian discourse. ${ }^{7}$

\section{Delineating a field}

When Stevin stressed the importance of first gathering definitions in his discussion of the 'restoration of the Age of the Sages', he gave a seemingly trivial example: he explained how, when interacting with practitioners such as masons or carpenters, he would first ask them the meaning of the specific words they used in their practice, after which he would write these down and learn them by heart. Having learned them, he was then able to interact fluently with these practitioners. ${ }^{8}$ This example seems trivial, because it suggests that defining is merely about learning the meaning of words. ' But when we approach the example from the perspective opened up by the ideal of a reduction to art, there is a more illuminating way to understand its importance. By introducing specific terms of art, these definitions drew attention to the relevant characteristics of the practical situation under consideration. By learning the meaning of these words, Stevin also learned to see which aspects of their practice were of special importance for these practitioners. Good definitions should thus in the first place communicate the relevant characteristics of the situation under consideration - where relevance is always relative to what one wants to be able to achieve.

In his Bewysconst, Stevin had already explained that he translated definitio with the Dutch bepaling because this has the primary meaning of demarcating a piece of land by surrounding it with poles or palen..$^{10}$ Accordingly, definitions must primarily succeed in properly delineating the field of study, and it does not matter how they achieve this. In this context, Stevin explicitly stated that he did not distinguish between definitions that are descriptive (by giving predicates that can be used to describe the subject corresponding to the term that is defined), explanatory (by merely indicating the meaning of words), or essential (by giving the essence of the subject). He justified this position with two revealing reasons: he appealed to the authority of mathematical authors such as Archimedes, and he strongly doubted the actual possibility of giving essential definitions privileged by philosophical authors such as Aristotle. ${ }^{11}$

Let us now consider Stevin's The Principles of the Art of Weighing with this in mind. The definitions introduce the general subject matter of the work, the crucial properties of the bodies' 
weight, and the kind of configurations that will be addressed. The latter configurations single out geometrically significant relationships within the instruments used for weighing bodies, by 'explanatorily' introducing specific terms for them, such as 'beam', 'handle' and 'fixed point'. The most important properties of weight (which is 'descriptively' defined as the known value of a body's 'power of descent in a given place' ${ }^{12}$ ) have to do with the bodies' center of gravity, which Stevin 'descriptively' defined as 'the point such that if the body is conceived to be suspended from it, it remains at rest in any position given to it'. ${ }^{13}$ The subject matter of the book is defined as 'the ratios, proportions, and properties of the weight or gravities of bodies'. ${ }^{14}$

There is one further definition that merits comment, as it shows the crucial importance of Stevin's use of anaphora in his text. In definition XI, Stevin introduced the neologism evenstaltwichtigh to denote two gravities that keep each other in equilibrium. The need for a specific term is clear from the fact that two such gravities will in general not be of equal weight (and thus evenwichtigh or equiponderant). Evenstaltwichtigh bodies only have the appearance of equal weight, but the real equality is one according to their position (' $n a$ den ghestalt). ${ }^{15}$ The requirements of textual presentation prompted Stevin to introduce this term, which was needed to avoid ambiguous expressions - but in the same move, it allows the reader to adopt a more abstract perspective on the situations described. The possibility of using the same term to describe a whole array of situations shows that there is a way in which they are all crucially similar. Bringing out the mathematical characterization of this similarity was the main goal of Stevin's treatise. Knowing the general conditions under which bodies are evenstaltwichtigh will allow any practitioner to reach his goals efficiently in all particular circumstances, once these are properly described, and will thus successfully reduce the field of operations involving heavy bodies to the form of art. As we will see, this knowledge is grounded in two fundamental propositions: the law of the lever and the law of the inclined plane.

\section{Demonstrating the law of the lever and the law of the inclined plane $e^{16}$}

The first proposition of The Principles of the Art of Weighing establishes the law of the lever. By assuming that equal bodies are in equilibrium when hanging from equal distances, Stevin was able to prove that if a heavier body is evenstaltwichtigh with a lighter one, the distances from which they are hanging have the inverse ratio of their weights. ${ }^{17}$ The proof is based on the similarity of both situations which can be almost directly visually ascertained in Stevin's first diagram (see fig. 1). The whole body $A B C D$ is in equilibrium when suspended from its center $T$ (which can be considered its center of gravity), since we can imagine it to be two equal bodies hanging from equal distances - and everyone agrees that these will be in equilibrium. If we now mentally divide the body into two unequal bodies rather than two equal bodies, they will also be in equilibrium, as long as they are suspended from the same point. For example, we can take the heavier body to be $L M D A$ and the lighter $L M C B$, which have their own respective centers of gravity located in $S$ and $X$ (since these points divide the bodies again into equal parts). It is now easy to see that the distances of the centers of gravity of these supposedly evenstaltwichtigh bodies to their point of suspension $T$ are inversely proportional to the weights of the bodies (as represented by their magnitudes).

The validity of the demonstration rests on two related, crucial steps: the assumption that the unequal bodies will indeed remain in equilibrium when we actually hang them from their respective centers of gravity, and the further assumption that the shape of the bodies does not 
matter (such that the inverse proportionality established can be interpreted as proving the stated proposition in full generality, as shown in fig. 2, where Stevin replaced the regular bodies $L M D A$ and $L M C B$ with irregular bodies of the same weight). What is of interest here are the judgements of similarity that lie at the basis of both steps: that the situation with the irregular unequal bodies is similar to the one with the regular unequal bodies, which in turn is crucially similar to the one with the solid body hanging from its middle, so that the initial equilibrium will not be disturbed under these imaginary replacements. Crucially, these similarities can only be noticed once one has identified a body's center of gravity as being of special interest. Its definition draws attention to the existence of a uniquely privileged point within all bodies: if we want to neutralize the effect of a body's gravity, we have to suspend the body either from its center of gravity, or from somewhere in the vertical going through it (this is implicitly assumed throughout Stevin's treatment, and made explicit in a comment on proposition 6, where it was called a 'common rule in the Art of Weighing ${ }^{18}$ ); and if we suspend it from somewhere else, the body's non-balanced gravity will cause a motion that will stop when the body has reached its preferred position as determined by the center of gravity (this is further elaborated upon in propositions 6,7 and 8 of Stevin's treatise). In other words: the center of gravity is the unique point at which we can imagine all of the body's weight to be concentrated - and it is the latter idea that underwrites both steps of the demonstration.

The demonstration of the law of the lever can be usefully understood along the following lines. ${ }^{19}$ It is assumed (1) that all bodies possess a unique center of gravity (in which, for the reasons stated, their weight can be thought to be concentrated), and (2) that we can all agree that for symmetrical bodies this point is located in the geometrical center. The mathematical proof then shows how to determine the location of the center of gravity of composed bodies: it is the place from which the distances will be inversely proportional to the weights of the composing bodies. The proof thus brings us from an almost purely qualitative characterization of the center of gravity to a precise quantitative determination.

In the appendix to the volume containing The Principles of the Art of Weighing, Stevin criticized an alternative demonstration of the law of the lever. ${ }^{20}$ Taking inspiration from the Aristotelian Mechanical Problems, some authors had claimed that the cause of unequal bodies being evenstaltwichtigh could be found in the circles they would describe under the conditions stated: the smaller body would describe a proportionally greater circle, and the greater body a proportionally smaller circle. Stevin merely pointed out that since bodies in equilibrium do not move, these postulated motions cannot be part of the cause of the equilibrium. Starting with Duhem, he has often been criticized for not having seen the potential fruitfulness of this approach, which can be supposed to have led to the principle of virtual velocities. ${ }^{21}$ For our purposes it is more interesting to point out that Stevin also emphatically stated that the true cause of evenstaltwicht was to be found in that which has been proved about it mathematically' in the demonstration of the law of the lever. Crucially, he added that these other authors' inability to devise the causes was related to the fact that they could not 'reduce to the form of an Art of Weighing' (sonder te crijghen form van Weeghconst) - thus explicitly relating the goal of reduction to art to knowledge of causes.

The preceding analysis makes clear how, according to Stevin, the mathematical demonstration would have been able to uncover a cause. Two bodies are evenstaltwichtigh because their configuration is one that can be mathematically transformed into one where their common weight is distributed evenly around the point of suspension; and the possibility of such a transformation rests on the fact that all bodies do have a unique center of gravity. In this way, the 
mathematical law is nothing but the encoding of the similarity between these different configurations, and it is this similarity that provides the appropriate causal grounding. We will further analyze how this idea relates to the possibility of a successful reduction to art in the next two sections, but first we will consider the second foundational proposition underlying this reduction, the law of the inclined plane.

The cause that grounds evenstaltwicht on an inclined plane can be understood along the same lines, although in this case the underlying similarity is easier to miss. Stevin famously demonstrated that when two connected bodies are lying on two inclined planes that form an upright prism, equilibrium will necessarily follow when their weights have the same proportion as the lengths of the planes. The demonstration consists in showing that if this were not the case, a perpetual motion would follow for a wreath lying around this prism consisting of connected equal spheres lying at equally spaced distances (since each postulated motion of the wreath would reproduce the original situation, with the number of spheres lying on each of the inclined planes determining the relevant weights stated in the condition; see fig. 3, which again allows one immediately to see that this is the case). Crucially, the perpetual motion that is excluded by Stevin is one that starts spontaneously, a fact all too often passed over in silence by commentators, but explicitly stated by Stevin. This is important, because we are dealing with heavy bodies, which by definition have an intrinsic tendency to descend; and as we saw, if their resulting motion is limited by the presence of fixed constraints, they also have a preferred position where they will come to rest, as determined by the relative position of their center of gravity and the constraints. The wreath of spheres lying around the prism can be considered a composite, heavy body: claiming that it could spontaneously start its motion by its weight, but that it would not reach a position of equilibrium, would amount to claiming that this body was completely dissimilar to bodies characterized by a center of gravity. It is the latter fact that Stevin judged to be absurd. It is thus again the underlying similarity of this situation to that of a body suspended in or above its center of gravity that gives this proportion its causal grounding. ${ }^{22}$

\section{Disclosing the causes of the properties of the balance}

Stevin's complete reduction to the form of art rested on a preliminary division of the field of operations, as shown in the dichotomous table at the very beginning of The Principles of the Art of Weighing. It announces that the text will deal with four kinds of basic situations: vertical lowering weights, vertical lifting weights, oblique lifting weights and oblique lowering weights. The proportions stated by the different propositions will characterize the forces exerted by these weights in terms of the weight of the body to be held in equilibrium by them and the geometry of the situation, where the main division is between the forces exerted in a vertical direction and those exerted in an oblique direction. These propositions are based on the two fundamental propositions just analyzed: the law of the lever for vertical forces, and the law of the inclined plane for oblique forces, respectively.

As we have seen, the demonstrations of these two laws were implicitly based on physical facts involving bodies' centers of gravity, and more specifically on considering the body composed of any two bodies as also having a single center of gravity that remains invariant through the replacements (for the law of the lever) or through the counterfactual motion (for the law of the inclined plane). The conclusions were anaphorically formulated in terms of each composing body's 
staltwicht, though, which has the important advantage that it allows one to focus on the effect that each of the bodies has on the other; i.e., it allows one to interpret the mathematically demonstrated proportions as characterizing forces. In a further move, Stevin abstracted away from the inclined plane as a physical device, until it only represented the triangle of forces implicit in the law of the inclined plane that gives a general recipe for determining forces exerted in an oblique direction (see fig. 4). ${ }^{23}$

Based on his two fundamental propositions, Stevin was in a position to 'disclose the causes of the properties of the balance from their grounds'. ${ }^{24}$ This disclosure further extends the realm of relevant similarities, by exploiting the power of proportional reasoning. Manipulating mathematical proportions, it becomes easy to translate the basic cases into other cases with different geometrical configurations of forces and weights - but still characterized by equilibrium. Perhaps the most relevant instance is given by proposition 20 , which shows how to relate vertical lifting weights (grounded in the law of the lever) to oblique ones (grounded in the law of the inclined plane):

If there is in the axis of the prism a fixed point and a movable point, at which it is kept in a certain position by a vertical lifting weight and an oblique lifting weight: as the vertical lifting line is to the oblique lifting line, so is the vertical lifting weight to the oblique lifting weight. 25

The accompanying diagrams show how to recognize the relevant elements of the proposition in different situations, situations that are all essentially similar to the mathematical perspective opened up by Stevin's new art of weighing (see fig. 5). Looking at the diagrams, the reader is taught immediately how to isolate the crucial ratios that determine equilibrium - thus disclosing the causes.

Proposition 20 brings a further, related aspect of Stevin's reduction to our attention. In the preface to his work, where he extolled the superior qualities of the Dutch language, he had referred to the formulation of this proposition as a crucial example. Stevin's defense of Dutch as a scientific language was obviously connected both to a broader reassessment of the status of the vernacular in the late Renaissance, and to the specific political context of the newly-emerging nation in which he wrote his books. But it is important not to lose sight of the fact that his insistence on the cognitive reasons for this superiority had an intrinsic connection to his ideal of reduction to art. Dutch was the most perfect language, according to Stevin, because of the combined effect of the high prevalence of monosyllabic words that correspond to simple things in nature and the possibility of combining these words to form new words, the meaning of which is perfectly clear from that of their composing parts. ${ }^{26}$ This made it eminently suitable for teaching the arts, as shown by the ease with which complex propositions such as the one presently under consideration could be perspicuously expressed. The compositional nature of Dutch allowed the terms to be permuted in the right order: 'Ghelijck rechtheflini tot scheefheflini, alsoo rechthefwicht tot scheefhefwicht'. ${ }^{\text {' }}$ As in the proofs of the two basic propositions, the printed diagrams and the words of the accompanying written text jointly rendered the relevant structures transparent for the reader.

It is no coincidence that Stevin chose the formulation of a proportion as his crucial example. Proportional reasoning was the central engine of his reduction to art, by which one could show that a whole field of operations (in this case those involving heavy bodies) could be covered by the same principles. Moreover, Stevin had already introduced the term 'proportion' itself as a general example of the superiority of Dutch in the Benysconst. The Dutch term evenredenheyt expressed its content directly: 'Evenredenheyt is de Evenheyt der Redenen' (in contrast to, e.g., its 
abstruse Latin rendering: 'Proportio est Rationum similitudo'). As a result, the term could be used directly to guide correct applications. ${ }^{28}$ Formulating the goal as a search for relevant evenredenheden immediately made it clear that one was looking for ratios that remain invariant throughout different configurations. Significantly, Stevin often used reden (which primarily means 'reason' or 'ratio') as almost directly synonymous with oirsaeck or cause (as is possible in many languages). ${ }^{29}$ An evenredenheyt could thus be understood as simultaneously expressing a mathematical relationship and a causal equivalence.

\section{Formal causality and the arts}

Stevin's way of using of causal language to describe his mathematical art of weighing was perfectly consistent with his denial of real definitions expressing underlying essences in the Bewysconst. Indeed, in that same work he also approached causal structures from the perspective of human agency rather than that of essential powers inhering in natural things. ${ }^{30}$

Stevin opened the Benysconst with definitions of the four traditional causes: material, formal, efficient and final; but he used them exclusively to refer to artificial constructions where the causes jointly result in an effect that he called the werck or daet. Stevin silently transformed the fourfold distinction from an ontological description of the structure of all natural events into a pragmatic scheme that could be used to characterize everything that is done by art. ${ }^{31}$ To give an example, similar to Stevin's own of the beer barrel: a mechanical practitioner (efficient, or 'making' cause) constructing a balance (effect or daet) by imposing a certain geometrical configuration (formal cause) on some pieces of iron (material cause) to be able to weigh bodies accurately (final cause).

According to this scheme, the theoretical art of weighing is completely devoted to investigating the formal cause. ${ }^{32}$ Again, the explicit definition that Stevin gave of a formal cause superficially appears as though it focuses on purely verbal questions: 'Form is the cause out of which the matter receives the name of some species'. ${ }^{33}$ In this case, the resulting material object will be called a balance, because the geometrical structure imposed upon the matter makes it suitable for performing a specific kind of operation, i.e., weighing. It is the latter suitability that is guaranteed by the theoretical analysis of 'the causes of the properties of the balance'. All 'formally' possible configurations of the balance are determined by the realm of relevant similarities underlying the propositions proven in the art of weighing that allow these configurations to play their causal role. Or to put it differently: these similarities provide appropriate causal grounding because they determine the extension of the species 'configurations in equilibrium' to which all balances belong. This does imply that the causal status of claims ultimately depends on our classificatory interests. Discovering causal factors comes down to identifying the structural features of systems that allow them to be classified in specific ways.

Stevin's causal scheme from the Bewysconst also gives us more insight into Weeghconst and Weeghdaet. Whereas the theoretical book on the art of weighing was limited to an abstract study of the formal cause, the other book, which was published simultaneously (its title can be translated as the 'The Practice of Weighing', following Stevin's own Latin annotation), dealt with the effects that could be achieved when the formal configurations uncovered by the theoretical investigation were imposed on matter by practitioners in order to achieve their goals. 


\section{Coordinating theory and practice, cause and effect}

Stevin's book on the Weeghdaet was devoted to teaching its readers to recognize the theoretically established proportions in material constructions. It shows how our basic ways of dealing with heavy objects in practice exemplify certain configurations of forces, helping us to achieve our goals. By translating practical challenges in terms of the staltwicht of objects involved, it becomes possible to make efficient decisions regarding the proper actions to be taken or instruments to be used in diverse circumstances (see, e.g., fig. 6). By reducing mechanical knowledge to the form of art, Stevin thus rationalized the structure of our practical actions in a way that also allows us to extend our initial know-how to ever-new situations that can be brought under our control. In several places, Stevin commented that he only gave a few examples, and that these should suffice to clarify how to affect the coordination between theory and practice. After this, one should be able to translate other situations at will by drawing the appropriate diagrams. ${ }^{34}$

As a reduction to art, Stevin's theoretical treatment started with a practical field that was already partly articulated by know-how. For example, he commented on how people had noticed the effect of a longer lever arm in practice, before gaining any theoretical insight into the underlying mathematical proportions. ${ }^{35}$ This prior experience of heavy bodies helped delineate the field by drawing attention to crucial aspects that should be incorporated into the theoretical treatment. This is why it was so crucial to Stevin to appeal to very simple, qualitative experiences that could help ground his theory. After having stated propositions 6, 7 and 8 in the $W$ eeghconst (the crucial importance of which was already stressed above, since they describe the different kinds of equilibrium that result from the relative position of a body's center of gravity with respect to its fixed point), Stevin added that 'If anyone should wish to see the contents of the preceding three propositions by some experience, he might take a ruler of wood'. By making some holes in the ruler and making it freely pivot around a needle that had been put through these holes, one would immediately see the qualitative truth of these propositions for this simple object. ${ }^{36}$

Thus, it is no coincidence that the first proposition of the Weeghdaet explained in detail how to practically (werckelick) find any body's center of gravity through a combination of simple operations of suspension. Given that it is the most important notion in the theoretical elaboration, it was crucial that everybody could acknowledge its practical existence. It is revealing to compare this first proposition to the first proposition of Stevin's text on practical geometry, the Meetdaet, which explained how to construct a straight line using a number of different methods. ${ }^{37}$ We can see this proposition as providing instructions on how materially to perform the crucial elementary operation that was already given, purely theoretically, by Euclid's first postulate. This shows that more complicated, theoretically-established propositions can 'in principle' also be applied to empirical situations, since their validity depends on this postulated possibility. Exactly the same role is played by the first proposition of the $W$ eeghdaet. If you can constructively determine any given body's center of gravity, you can 'in principle' construct all configurations of material bodies in equilibrium. As in the case of geometry, reducing a practice to the form of art involved the identification of elementary operations that allowed one to ground the coordination of the practice with an elaborated theoretical structure.

Note how Stevin defined theory in the later text on the 'restoration of the Age of the Sages': 'Theory [Spiegheling] is an imaginary operation [verdochten handel] without natural matter' ${ }^{38} \mathrm{He}$ had likewise opened The Principles of the Art of Weighing with the characterization of its subject matter as 'gravity, dissociated in thought [duer t'ghedacht ... gheweert] from physical matter', ${ }^{39}$ and defined the 
center of gravity as 'the point such that if the body is conceived to be suspended [door ons ghedacht hanghende] from it, it remains at rest in any position given to it'. He commented on the latter definition by stressing its imaginary character: it is a suspension that is only effected in one's mind. ${ }^{40}$ Following Stevin's use of the Dutch term spiegheling (speculation or reflection) for theory, we can understand these imaginary operations as ideally 'mirroring' the structure of practical activities: theoretical structures are in the first place linked to possibilities for acting - and we can see the stylized hands suspending the geometrical bodies in Stevin's theoretical treatise (see the figures above) as striking visual reminders of this crucial link. It is only through this speculative reduction to art that the structure of our practical activities can for the first time be fully and transparently articulated.

The second proposition of the Weeghdaet played a similar role to the first one, but it also brought a further kind of consideration into play. This proposition described how to construct 'a most perfect balance', one that would remain at rest in any position it was given, thus directly exhibiting the defining property of a body's center of gravity for bodies of more complex shape than the simple wooden ruler already alluded to in the Weeghconst. But this object also had its own practical use as a measurement instrument for establishing precise quantitative relationships. The conditions for such precise measurements were further analyzed in propositions 2-6. In the last of these propositions, Stevin described a small device that he called an oblique balance, with which 'to make us see, examine, and understand through visual experience the truth of the propositions on the proportionality of oblique weights'. He thus introduced an instrument for the measurement of oblique forces that could play the same role as the 'most perfect balance' did for the vertical forces. $^{41}$

These propositions were absolutely crucial to establish in full the coordination between theory and practice. The conditions required for high precision instruments were theoretically established, but could never be perfectly verified in practice due to the limitations of working with material objects. Stevin explicitly allowed that practitioners had to decide how closely they needed to approximate these conditions for the purpose at hand $;^{42}$ but his detailed description, with an eye to the empirical challenges encountered, clearly revealed that he supposed that these approximations could in principle always be improved upon. In his later reflection on reduction to art in the text on the 'restoration of the Age of the Sages', he formulated the relationship between theory and practice as follows: 'The property and the end of theory is that it furnishes a sure foundation for the method of practical operation, in which by closer and more painstaking care one may get as near to the perfection of the theory as the purpose of the matter requires for the benefit of man'. ${ }^{43}$ The possibility of this ever-closer approximation was thus an essential part of the successful reduction to art, as it guaranteed the relevance of the theoretically proven, mathematically exact proportions.

After the first six propositions, Stevin considered situations for which such approximation could nevertheless not be expected. In the preface, he had already warned his reader not to mistake this for a defect of the theory. ${ }^{44}$ When machines are put into motion to realize useful effects, this inevitably brings material impediments to this motion that cannot be eliminated in any way. ${ }^{45}$ But given the successful establishment of the first six propositions, this should no longer worry us unduly. We are now in a position legitimately to ascribe the differences between theoretically proven proportions and practical results to the effect of material disturbances on the 'ideal' phenomenon. 
The theoretical proportions remain relevant for the latter kind of situations, since we can trust them to articulate correctly the structure of the situation we are analyzing. Consider, for instance, the situation in fig. 7: if the force applied by the man is to the weight of the load $H$ as $K G$ is to $E G$ (the radius of the axle around which the rope pulling the load is being coiled), this will in theory keep the load in equilibrium. Again, in theory, the smallest additional force would suffice to start raising the load - but in practice this will of course not be the case, because of the material impediments that need to be overcome. We do not know in advance how much more force we will actually have to exert to move the load, but we do know that the force determined by the theory is the minimum force: it puts a theoretical limit on the operation of the machine. The same theoretical consideration also tells us how to identify the relevant causal factors that might be taken into consideration if we want to adapt the machine to new circumstances (e.g., if we wanted to move a heavier load or if less force were available).

The last proposition of the $W$ eeghdaet provides the most spectacular example of this way of structurally linking theory to practical challenges. It introduced a machine that Stevin daringly called bet Almachtich ('the Almighty'). ${ }^{46}$ This machine was proposed to actualize the theoretical possibility of producing a multiplication of power that could in principle be indefinitely extended, such that any conceivable practical challenge could be met. The machine basically consists of a system of geared cogwheels that multiply an initial force delivered with a crank and transmit the output force using a windlass. Stevin stressed the practical advantages of his design over alternatives, due to the sturdiness of its construction, the continuous nature of its output motion, and the ease with which parts of the system could be disengaged, depending on the amount of multiplication that was needed for the task at hand. ${ }^{47}$ Yet it is not simply a practical machine, as is made clear by its provocative name. Having illustrated its use to haul a ship over a dam, Stevin went through elaborate calculations to show the effects of adding more and more gears to the system, until he finally concluded that this would allow a mere child to move the earth, thus making true on Archimedes' famous boast. But, he added, continually operating the machine over a period of ten years would have only lifted the earth a distance of 1/2,400,000,000,000,000 feet.

The clearly fantastic nature of this last example raises a question about its place in Stevin's Weeghdaet. The general focus of the treatise is on the challenges posed by concrete materiality, but it is obvious that this postulated motion would never take place, due to all the imperfections that would arise in the transmission of the motion and the stresses that would be put on the whole device. The discussion seems to have been included with a dual purpose. ${ }^{48}$ On the one hand, the play with immense numbers (all printed in full, some with more than thirty digits) was no doubt intended to dazzle the reader. On the other hand, and more importantly, the comments on the time spent and distance moved that accompanied these numbers simultaneously pointed in another direction: they warned the reader that multiplication of force must always be balanced against other factors. And this last point does have important practical implications. It is no coincidence that having gone through these spectacular extrapolations, Stevin ended his book by returning to some of the Almighty's practicable applications, by giving some examples of tasks for which it would be suitable - but added, tellingly, that he would not enter into any further discussion of these, since the reader who had followed his discussion would know best how to adapt the machine 'according to the occasion'. ${ }^{49}$ This adaptation to particular occasions crucially includes considerations involving the balance between multiplication of available force, distance moved and time spent: depending on the challenge, a different balance will need to be struck. Theory shows that such 
choices have to be made, but it does not dictate which one is right. At this point, the practical intelligence of the practitioner necessarily takes over.

This last point highlights the importance of 'the occasion' for correctly understanding the relationship between theory and practice. ${ }^{50}$ It is never a matter of simply 'applying' theory, but rather one of guiding the process of situationally determined, practical decision-making by mathematically explicating the structure of a range of possible actions and their effects.

All the foregoing should also allow us to better gauge the place of mathematical reasoning in Stevin's proposed reduction to art. We start from a set of qualitative observations that draw our attention to a number of significant phenomena. Theoretical speculation shows that these qualitative observations in principle allow the establishment of precise quantitative relationships. These relationships can indeed be exemplified to a very good approximation in well-determined material circumstances. Mathematical reasoning furthermore allows the identification of a much larger class of situations that are - in principle - also similar to these cases. Even if precise quantitative relations can no longer be empirically exhibited for this larger class, mathematics has still played a crucial role. It has allowed the identification of a causal structure underlying the messy empirical situations that puts theoretically-determined constraints on what we can and cannot put into effect.

There is one last aspect that needs to be commented upon. We saw how the existence of a unique center of gravity was absolutely crucial for the theoretical articulation of the causal structures in question. Stevin was well aware that this could only be assumed under specific circumstances. ${ }^{51}$ If we were to take into consideration that all material bodies' 'power of descent' is actually directed towards the center of the world, then we would have to conclude that only perfectly spherical bodies have a unique center of gravity; for all other bodies, there would be no longer a 'point such that if the body is conceived to be suspended from it, it remains at rest in any position given to it' (see fig. 8, where the balance would need to be supported at a different point to be kept in equilibrium when no longer oriented horizontally). We can safely ignore this complication, though: the scale of our instruments is so insignificant with respect to the size of the earth that any convergence of directions must remain imperceptible. But this does imply that the causal structures uncovered by Stevin's art of weighing must again be relativized to a specific domain of reality that is singled out by the demands of our practical and classificatory goals. If we were to consider bodies on a different scale, it would no longer be possible to establish the relevant configurations described in the treatise as similar.

\section{Conclusion: 'this long-hidden matter'}

Stevin was rightly proud of having successfully reduced practical dealings with mechanical instruments to the form of an art. Archimedes' highly abstract mathematical treatise on the equilibrium of plane figures had been well known since its publication in 1544, and some important contributions to the medieval scientia de ponderibus had also been published by Tartaglia and had found their way into Cardano's popular writings, for example. Sixteenth-century Europe was also characterized by a rich material culture where skillful production and use of diverse mechanical contrivances played a central role. What was lacking was a way of clearly linking the theoretical treatment to this practical knowledge, which is exactly what Stevin excelled in doing. ${ }^{52}$ 
As I hope to have shown, this articulation of mathematically-structured theory on material practice also determined Stevin's perspective on how to uncover causal factors in the world. The main goal of his reduction to art was to show how a whole array of seemingly diverse operations could be seen as characterized by an underlying systematic unity - and this unity could also be seen as expressing a causal structure. In this way, the ideal of reduction to art implicitly introduced a strikingly un-Aristotelian epistemology of causal knowledge, in which causes could be identified through a combination of mathematical reasoning that isolates invariant ratios, and material construction that shows how to exemplify these mathematical structures.

Most of the themes we have been discussing came together in the opening paragraph of Stevin's dedication of his Principles of the Art of Weighing to Emperor Rudolph II:

That number, magnitude, and weight are in all existing things inseparable attributes, full of profound and useful properties, is attested not only by several scholars, but it is also known to all by experience in all things. It is also known that the first two, to the great profit of man, have reached the form of written arts, viz. arithmetic and geometry; but not so weight, because its fundamental properties have remained hidden from our predecessors. It is true that with regard to vertical weights it has been observed by experience that two evenstaltwichtigh gravities are proportional to their arms. But they thought that this proportionality was due to the circles described about the fixed point by the extremities of the arms. From which, as is usual with errors, there followed no knowledge of the causes. As to the oblique weights, these were not known at all, with the result that this subject matter could not receive the form of an art like the others. But when the situation changed, and this long-hidden matter was revealed through its fundamental principles, it at last reached this status, in the formal shape in which it is here being dedicated to Your Imperial Majesty. ${ }^{53}$

Stevin's recurring focus on the proper formal features of the 'written' presentation of any art parallels the role of formal causality as the Weeghonst's main subject matter, as explained in Section 5. In both cases, the central issue is how to dispose given matter in a structure that allows one to achieve certain effects. The discussion on the 'restoration of the Age of the Sages', summarized in Section 1 above, can thus be seen as intended as a description of the formal cause of all theoretical arts.

This resolutely structural perspective is in line with Stevin's translation of theoria as spiegheling (reflection or speculation), as noted above in Section 6. As Stevin (who also wrote a treatise on perspective and captoptrics) was perfectly well aware, one can never reflect the whole situation in which one finds oneself: by orienting one's mirror, one delineates that part of the situation which is of prime interest; as we saw in Section 2, this was the role of Stevin's theoretical definitions. The translation into the reflected form is then brought about by the propagation of light. The reflection shows a projection of the spatial relationships on a two-dimensional surface, where the relationships are presented purely in the light, abstracted from their original material relata. It is the light that writes the 'theoretical' or 'speculative' proportional relations, leaving formal traces that can be translated into action by the person who has learned to use the mirror. ${ }^{54}$ Abstracting away from matter to 'reveal' the formal relations that can be exploited in further practice is exactly what mathematics did for Stevin, as we saw in sections 3 and 4: it 'brought to light' what had remained 'hidden' in the obscurity of non-reflected forms of action. 


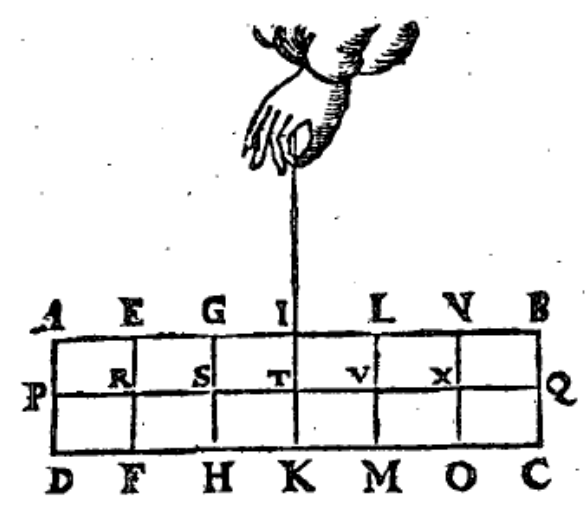

Figure 1: Demonstrating the law of the lever.

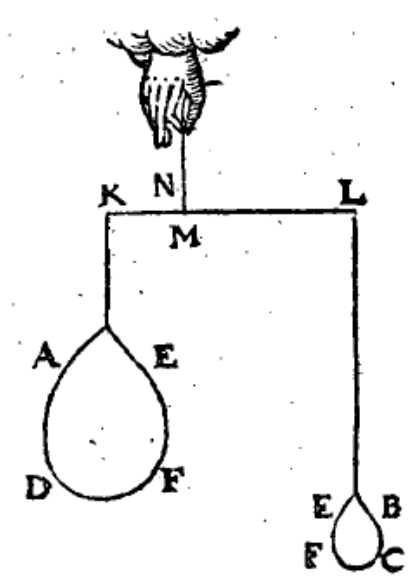

Figure 2: Generalizing to arbitrarily shaped bodies.

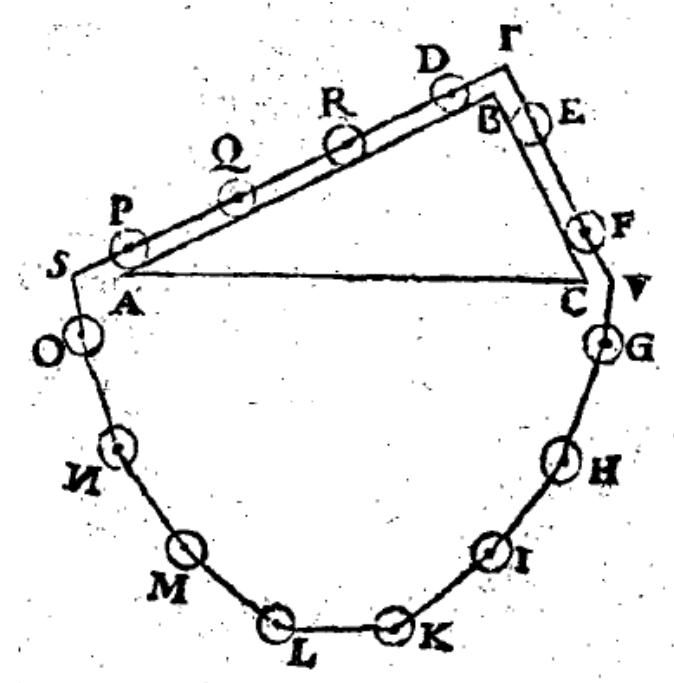

Figure 3: Demonstrating the law of the inclined plane. 

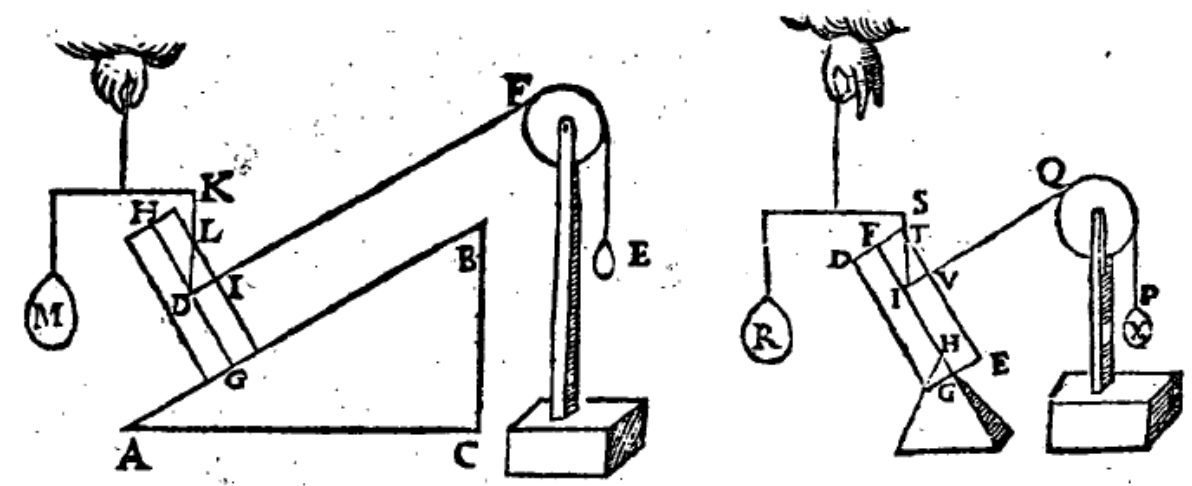

Figure 4: According to the law of the inclined plane, there is equilibrium if the weight $M$ of the body is to the weight of $E$ as $A B$ is to $B C$, which is in the same ratio as $L D$ to $D I$. This implies that the physical plane can be neglected in further considerations, as is done in the figure on the right, where triangle ITV encodes the relevant ratios.

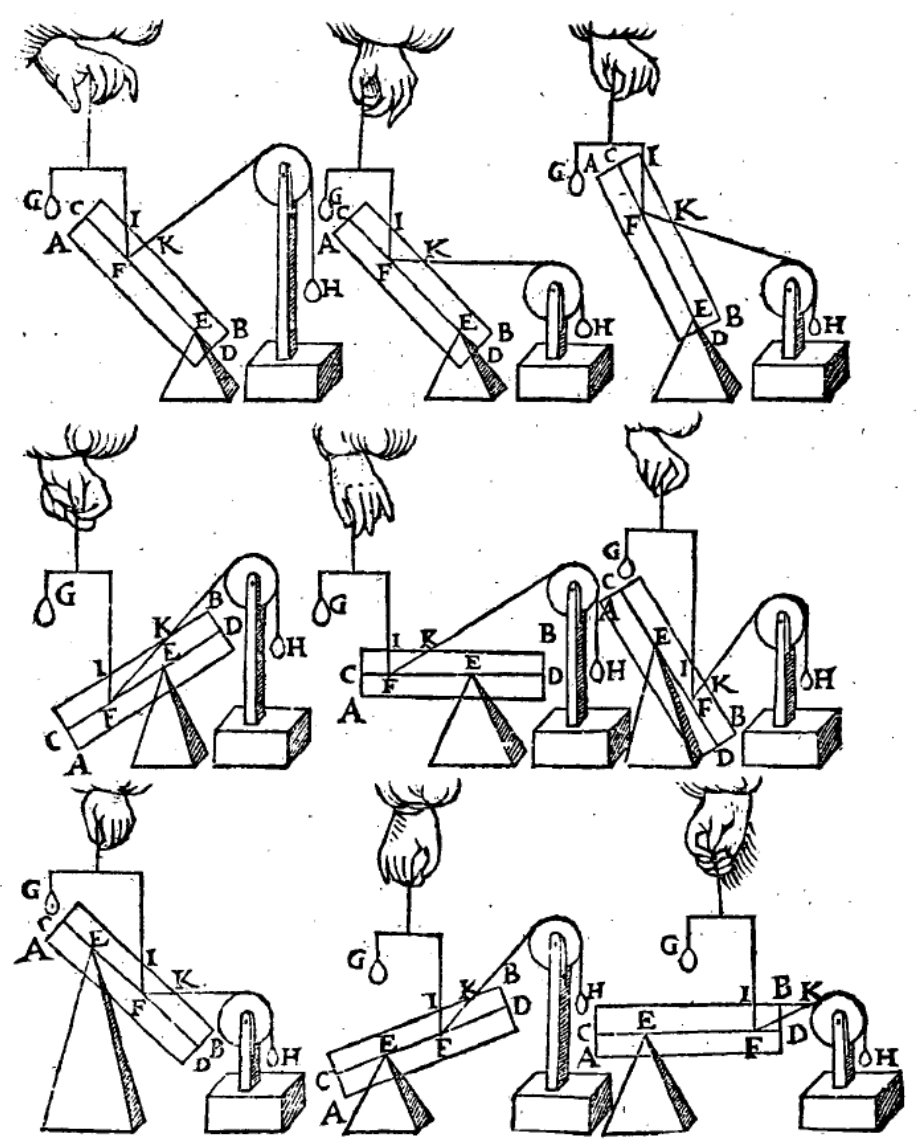

Figure 5: Systematically relating vertical forces to oblique forces. 


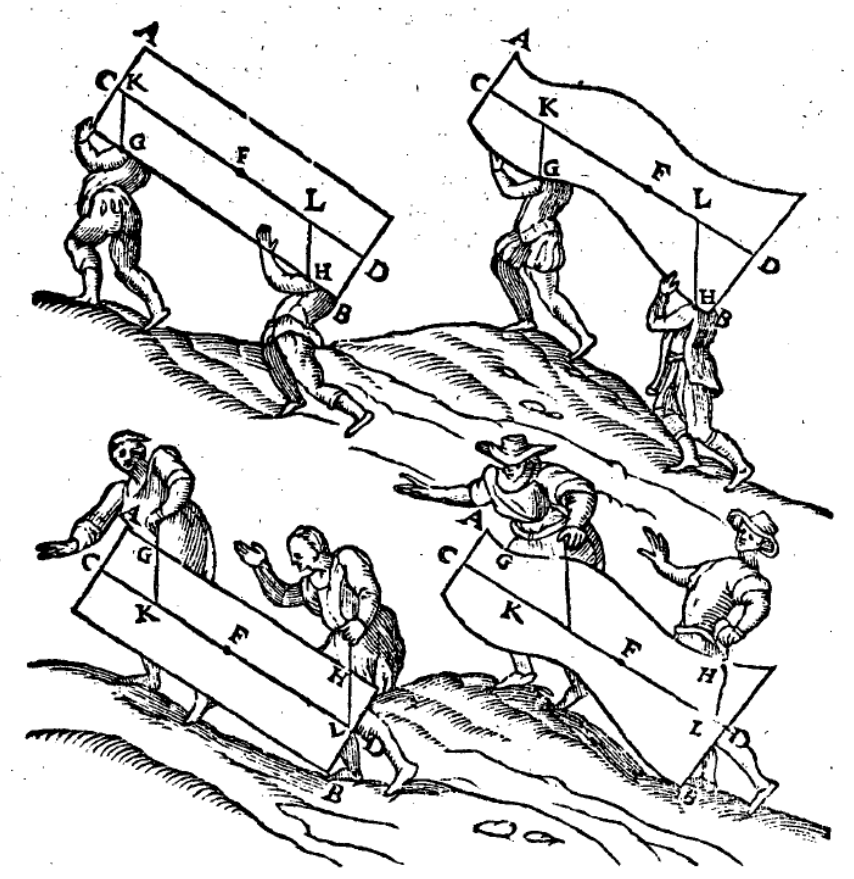

Figure 6: Translating a practical challenge into theoretical terms.

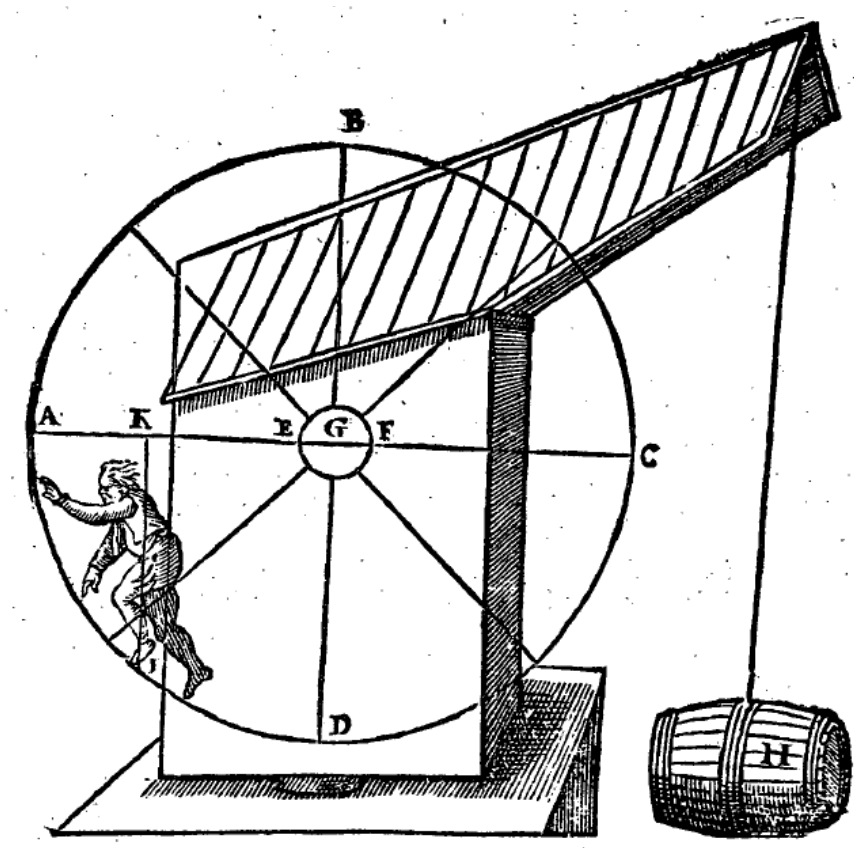

Figure 7: Putting machines in motion. 


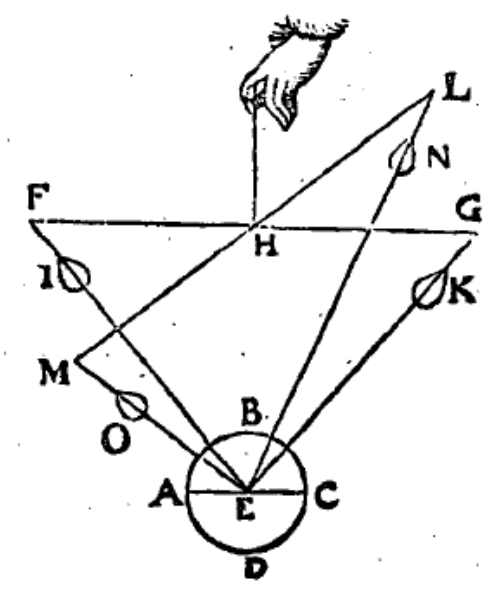

Figure 8: Non-uniqueness of center of gravity for weights along converging directions.

\footnotetext{
${ }^{1}$ For the influential use of the expression and a detailed analysis that is limited to the Italian context, see Rose, Italian Renaissance.

2 Stevin, Principal Works, I, 93. Here and in some of the following quotations, I adapt the translation given in the Principal Works, but I refer to the English translation for ease of reference.

${ }^{3}$ See Vérin, 'Rédiger', for an essential introduction.

${ }^{4}$ Stevin, Principal Works, I, 41-48. I present the components in a different order from Stevin, to streamline further discussion. The Principal Works only contains a partial translation of this text, cf. Stevin, Principal Works, III, 591-623.
}

${ }^{5}$ See Vérin, Gloire, 271-277, for further comments.

${ }^{6}$ See Descotes, 'Rhétorique' for a complementary approach that focuses on what the author calls Stevin's 'mathematical rhetoric'.

${ }^{7}$ See the chapter by Bunning in this volume.

${ }^{8}$ Stevin, Wisconstighe Ghedachtenissen, 1, 43.

${ }^{9}$ This is exactly the criticism that Arnauld and Nicole would later level against Stevin's definition of number in their Logique ou l'art de penser of 1662; as we shall see, Stevin had anticipated and dismissed this kind of criticism in his Benyssonst. See Naets, 'How to Define a Number', for further discussion with respect to Stevin's arithmetic.

${ }_{10}$ Stevin, Dialectike, 31, 121-122.

${ }^{11}$ See also Stevin, Dialectike, 53.

12 Stevin, Principal Works, I, 97.

13 Stevin, Principal Works, I, 99. Stevin took this definition from Pappus, and learned it from Federico Commandino's writings.

14 Stevin, Principal Works, I, 97.

${ }^{15}$ Stevin, Principal Works, I, 104.

16 This section contains a more elaborate discussion of some claims introduced in Van Dyck, 'Motion'.

${ }^{17}$ This is actually the converse of Archimedes' original proof, where it is shown that given the inverse ratio, equilibrium will follow. Stevin assumed without proof that the converse also holds.

18 Stevin, Principal Works, I, 139. The translation in the Principal Works, 111, renders 'ghemeenen Reghel' as 'general rule'; but Stevin had already introduced a number of postulates as known by 'ghemeene wetenschap', i.e., common (or maybe more precisely: commonly-shared) knowledge. This rule can thus be taken to have the status of a postulate, a shared element of the practice being reduced to art.

19 See Van Dyck, 'Epistemological Foundations', for more discussion.

20 Stevin, Principal Works, I, 507-509.

${ }^{21}$ Duhem, Origines, 267.

22 In 1644, Evangista Torricelli would be the first to render this similarity completely transparent by reducing the proof of the law of the inclined plane to a direct application of the general principle that the center of gravity of any composite body always takes the lowest position allowed by the constraints of the system: 
when the stated proportion holds, the center of gravity is already located in the lowest position possible. See Torricelli, Opera geometrica.

${ }^{23}$ See Dijksterhuis, Simon Stevin, 53-57 for further comments and analysis.

24 Stevin, Principal Works, I, 151.

${ }^{25}$ Stevin, Principal Works, I, 195.

${ }^{26}$ Stevin, Principal Works, I, 65. See Van der Wal, 'Logic, Linguistics, and Simons Stevin' for further discussion.

${ }^{27}$ Stevin, Principal Works, I, 91.

${ }^{28}$ Stevin, Dialectike, 156. On evenredenheyt, see also the chapter by Cohen and Kursell in this volume.

${ }^{29}$ In the preface to his book, for example, Stevin contrasts (in the translation given in the Principal Works) 'things we understand through their causes [oirsaeken] and those whose causes [redenen] are unknown to us', Stevin, Principal Works, I, 59.

30 Stevin, Dialectike, 4-9.

31 Of course, Aristotle also used the four causes to characterize artificial objects, but only as a way of motivating the fourfold division, which he then extrapolated to what were the central cases for him: the causes of natural events. This latter step is completely absent from all of Stevin's writings.

32 Machamer, 'Galileo and the Causes' already suggested relating the new mathematical sciences of the sixteenth and seventeenth century to formal causality, but without the level of detail offered here. Biener and Schliesser, 'Certainty' and Schliesser, 'Newtonian Emanation' further explore this in relation to the case of Newton, an author who was much more of a metaphysician than Stevin. Closer to Stevin, Mancosu, Philosophy of Mathematics, chapter 1, has discussed how appeals were regularly made to formal causality in an attempt to give mathematical demonstrations a causal status in the debates surrounding the Quaestio de Certitudine Mathematicarum.

33 Stevin, Dialectike, 6.

${ }^{34}$ E.g., Stevin, Principal Works, I, 333. Van den Heuvel. 'Architectuurmodellen', provides further analysis of Stevin's visual way of reasoning, with a focus on his work in architecture.

35 Stevin, Principal Works, I, 321-323.

36 Stevin, Principal Works, I, 143.

${ }^{37}$ Stevin, Principal Works, II, 771.

38 Stevin, Principal Works, III, 619.

${ }^{39}$ Stevin, Principal Works, I, 95.

${ }^{40}$ Stevin, Principal Works, I, 101.

${ }^{41}$ Stevin, Principal Works, I, 321.

42 Stevin, Principal Works, I, 306, 318.

${ }^{43}$ Stevin, Principal Works, III, 619.

${ }^{44}$ Stevin, Principal Works, I, 297-299.

45 See Van Dyck, 'Motion', and Van Dyck, 'Idealization', for further analysis of this claim and some of its consequences.

46 Jan de Groot made clear that the connotations of the name were not accidental, by rendering it as Pantocrator in his laudatory Latin poem that opened Stevin's treatise. Snellius's translation of Stevin's treatise in the Latin version of the Wisconstighe Ghedachtenissen published in 1605-1608 opted for the more cautious neologism of Pancratium; see Stevin, Mathematicorum Hypomnematum. Girard's French translation published in 1634 dropped all potentially problematic references altogether and simply referred to it as a cricq ('crank'); see Stevin, Oeuvres mathématiques, 480-481.

47 The States of Holland had already granted Stevin a patent for a device with which to haul ships over a dam in 1584, plausibly a version of the Almighty; see Dijksterhuis, Simon Stevin, 91. Stevin's dedication of the Weeghconst to Rudolph II refers to a patent that he would request for an 'unheard-of' contrivance, for the understanding of which the book contained the necessary theory (see Stevin, Principal Works, I, 65), which can again be interpreted as referring to the Almighty; and a patent granted to him a few months after the publication of the books on mechanics included the machine in a new device for dredging canals, with an explicit reference to the proposition from the $W$ eeghdaet (see Stevin, Principal Works, V, 35).

48 Stevin's discussion would be taken up by later authors such as Marin Mersenne and John Wilkins, who would again stress both sides, but with somewhat different purposes (see Van Dyck and Vermeir, 'Varieties of Wonder', for a discussion of Wilkins).

${ }^{49}$ Stevin, Principal Works, I, 373.

${ }^{50}$ See Vérin, Gloire, for a classic study of this aspect of engineering practice in the early modern period. 
${ }^{51}$ Stevin, Principal Works, I, 113-115.

52 The only work comparable in this respect to Stevin's was Guidobaldo del Monte's Liber Mechanicorum, which had been published in 1577, but which probably was unknown to Stevin (and which was conceptually less accomplished, as it lacked the resources to deal with forces exerted in any other direction than the vertical). See Van Dyck, 'Motion', for some further comments on the similarity between Stevin and Guidobaldo, and Bertoloni Meli, Thinking with Objects, for Stevin's place in the history of mechanics.

${ }^{53}$ Stevin, Principal Works, I, 55.

${ }^{54}$ Stevin explicitly comments on the link between theoretically-established propositions and mirror-images to justify his use of the term spiegheling in the posthumously published Materiae Politicae, 180-181. 